\title{
Cmax to Cmax Ratio Measurement
}

National Cancer Institute

\section{Source}

National Cancer Institute. Cmax to Cmax Ratio Measurement. NCI Thesaurus. Code C156579.

The determination of the ratio of one $\mathrm{Cmax}$ value compared to another $\mathrm{Cmax}$ value. The measurement may be expressed as a ratio or percentage. 